\title{
Pier Paolo Pasolini, poeta
}

Arlindo Rebechi Junior

Docente do Departamento de Ciências Humanas, da Faculdade de Arquitetura, Artes e Comunicação (FAAC) da Universidade Estadual Paulista (Unesp), atuando em diversos cursos na graduação e no Programa de Pós-Graduação em Comunicação. Doutor em Literatura Brasileira pela Faculdade de Filosofia, Letras e Ciências Humanas da Universidade de São Paulo.

E-mail: arlindo@faac.unesp.br

\section{UMA VIDA ENTRE POESIAS}

Notadamente, Pier Paolo Pasolini convive na lembrança de um público geral brasileiro por meio de suas obras cinematográficas. Isso se deve à grande repercussão que seus filmes tiveram desde os primeiros tempos de cinema novo. Da numerosa produção escrita de Pasolini, um intelectual praticante de uma gama considerável de gêneros literários - da prosa de ficção ao teatro em verso, passando pelo ensaísmo -, o leitor brasileiro mais atento talvez tenha se deparado com apenas uma ou outra narrativa do escritor italiano, dada sua restrição em termos de traduções ofertadas em português.

Dotado de uma coerência ímpar, que o aproxima, em termos de afinidades eletivas, ao cineasta brasileiro Glauber Rocha, Pasolini colocou lado a lado sua experiência pessoal e sua experiência histórica que negaria um mundo tecnocrático em favor de um mundo mais humanista e, portanto, resistente às mudanças sociais advindas pela maquinaria capitalista e suas formas agressivas de consumo de massa. O enfrentamento realizado por ele não seria tarefa das mais fáceis. Pasolini enfrentaria uma série de opositores - seja no plano político, seja no plano literário, seja no plano judicial, com seus inúmeros processos sofridos ao longo da sua vida.

O propósito aqui é oferecer ao leitor uma pequena mostra da produção escrita na forma de poesia desse arguto intelectual e poeta italiano. Afinal, Pasolini, como afirmou o escritor Alberto Moravia, é um raro "poeta civil", ou seja, um poeta cuja voz ultrapassará a alma de muitos e falará à nação como um todo.

\section{PIER PAOLO PASOLINI, POETA: A BUSCA PELA NERVURA DO REAL}

Natural de Bolonha, Pasolini nasceu em 5 de março de 1922, sendo o filho mais velho de uma professora e de um militar. É notável como o autor, sem 
privilegiar um gênero literário, tenha produzido em várias frentes intelectuais. Da sua crítica cultural, trouxe um ensaísmo de forte penetração em meios intelectuais, realizando incursões pelo cinema, pela literatura e pela cultura e política de sua época, tendo a coragem de apontar, sem meias palavras, os dilemas e assimetrias trazidos pela nova sociedade capitalista do século XX, forjada no consumo e nos tempos de comunicação de massa.

Como prosador, é notável sua desenvoltura e liberdade temática e de estilo desde as primeiras narrativas publicadas - a exemplo de Ragazzi di vita (Meninos de rua) (1955) e Una vita violenta (Uma vida violenta) (1959). Em terras brasileiras, não demorou a chegar o seu livro de prosa mais celebrado entre nós: Teorema (1969), traduzido apenas um ano depois da publicação na Itália.

Se o seu cinema já é um lugar de grande liberdade, no sentido de se constituir como um espaço que desafia os costumes sociais mais conservadores, a produção de poemas parece ser o espaço em que Pasolini se manifestou com o seu máximo impulso criador e experimental. Alfonso Berardinelli vai notar que por detrás de sua obsessão por escrever poesia estaria um princípio norteador das suas demais artes:

De fato escrever poesia para Pasolini era a mais natural das artes, uma atividade cotidiana da qual não podia prescindir, uma paixão originária e quase maníaca que lhe permitia o imediato reconhecimento de si mesmo: uma espécie de prática propiciatória, devocional, higiênica, da qual não podia abrir mão se quisesse manter ou reencontrar a fé em si mesmo. Se tivesse certeza de ser poeta, poderia tornar-se qualquer outra coisa: homem de cinema, crítico literário, ideólogo antiburguês e até, como aconteceu, um improvisado, mas original sociólogo da modernização italiana, sentida por ele, pessoal e literariamente, como o inesperado fim de um mundo secular'.

Aos seus 16 anos, de acordo com a pesquisadora Maria Betânia Amoroso, Pasolini descobre, por intermédio de um professor, o poeta francês Arthur Rimbaud. Tratava-se de um momento marcante para ele, em que "se encontra diante de algo absolutamente distante do oficialismo, do academicismo e do provincianismo que dominavam a escola italiana" ${ }^{2}$. Dali em diante, Pasolini levaria muito a sério o ofício de poeta.

1. BERARDINELLI, Alfonso. Pasolini, personagem poeta. In: PASOLINI, Pier Paolo. Poemas: Pier Paolo Pasolini. Trad. e notas Maurício Santana Dias. São Paulo: Cosac Naify, 2015, p. 15

2. AMOROSO, Maria Betânia. Pier Paolo Pasolini. São Paulo: Cosac Naify, 2002, p. 15-16.

\section{PRIMEIRAS INCURSÕES: O DIALETO FRIULANO}

As primeiras poesias de Pasolini trazem em si um dado bastante significativo que demonstra uma escolha, por assim dizer, resistente do poeta, numa Itália que se moldava, sob o crivo fascista. Em 1942, o primeiro livro de poemas de Pasolini, intitulado Poesie a Casarsa, foi publicado no dialeto friulano, a língua falada em Casarsa, a cidade de sua mãe, Susanna Pasolini. Muitos dos poemas que apareceram nesse primeiro volume seriam, posteriormente, coligidos no livro La meglio gioventù (1954). Vejamos dois curtos poemas dessa primeira fase juvenil do poeta, em tradução de Maurício Santana Dias: 


\section{Dedicatória}

Fonte d'água de minha vila.

Não há água mais fresca que em minha vila.

Fonte de rústico amor ${ }^{4}$.

\section{Ao menino morto}

Noite iluminada, no fosso

cresce a água, mulher grávida

vagueia pelo campo.

Lembro-me de ti, Narciso, tinhas a cor

da noite, quando os sinos

dobram os mortos ${ }^{5}$.

A opção em construir poemas no dialeto friulano, muito falado entre os camponeses do norte da Itália, pode ser pensada sob várias perspectivas. Sem dúvida, significa, primeiramente, uma atitude de enfrentamento ao que era tido como oficial pelo governo nacionalista de Mussolini. Pasolini, ligado à região por laços afetivos familiares, notava o forte enraizamento às tradições de um mundo rural, que, por si só, significava um forma de resistência aos moldes impostos pelo fascismo de então.

Essas primeiras poesias são resultados de um aprofundamento memorial com aquele mundo não urbano italiano. Tanto em "Dedicatória" como em "Ao menino morto", o poeta esforçou-se em criar imagens concentradas de uma paisagem regional, cujas ressonâncias remetem à primeira poesia de Federico García Lorca, muito estilizada, no caso do poeta espanhol, em temas e características das impressões e paisagens vindas da Andaluzia.

$\mathrm{O}$ interesse pelo mundo popular sempre foi um foco central na poesia de Pasolini. O poema "A melhor juventude" é talvez o retrato mais significativo da ligação do poeta italiano ao mundo do cancioneiro popular italiano. Datado de 1953, este poema, também escrito em dialeto friulano, é um dos últimos textos de sua obra Le meglio gioventù (1954). Cabe citá-lo na íntegra:

\section{A melhor juventude}

Senhor, estamos sós, já não nos chama mais!

Não nos escutas mais ano a ano, dia a dia!

Pra cá, nossos escuros pra lá, só Tua luz, não tens por nossos males nem ira nem piedade.

Passaram trinta séculos nada, nada mudou, todo o povo se uniu se uniu para o combate, mas nossas trevas são trevas de todos nós e apartar luz e treva só Tu mesmo é que sabes! Dias de lida! Dias mortos! Já desponta a carroça no rumo na estação pela praça quieta

3. Todas as citações dos poemas de Pasolini serão feitas a partir da competente tradução realizada por Maurício Santana Dias.

4. PASOLINI, Pier Paolo. Poemas: Pier Paolo Pasolini. Trad. e notas Maurício Santana Dias. São Paulo: Cosac Naify, 2015, p. 25. 5. Idem, ibidem. 


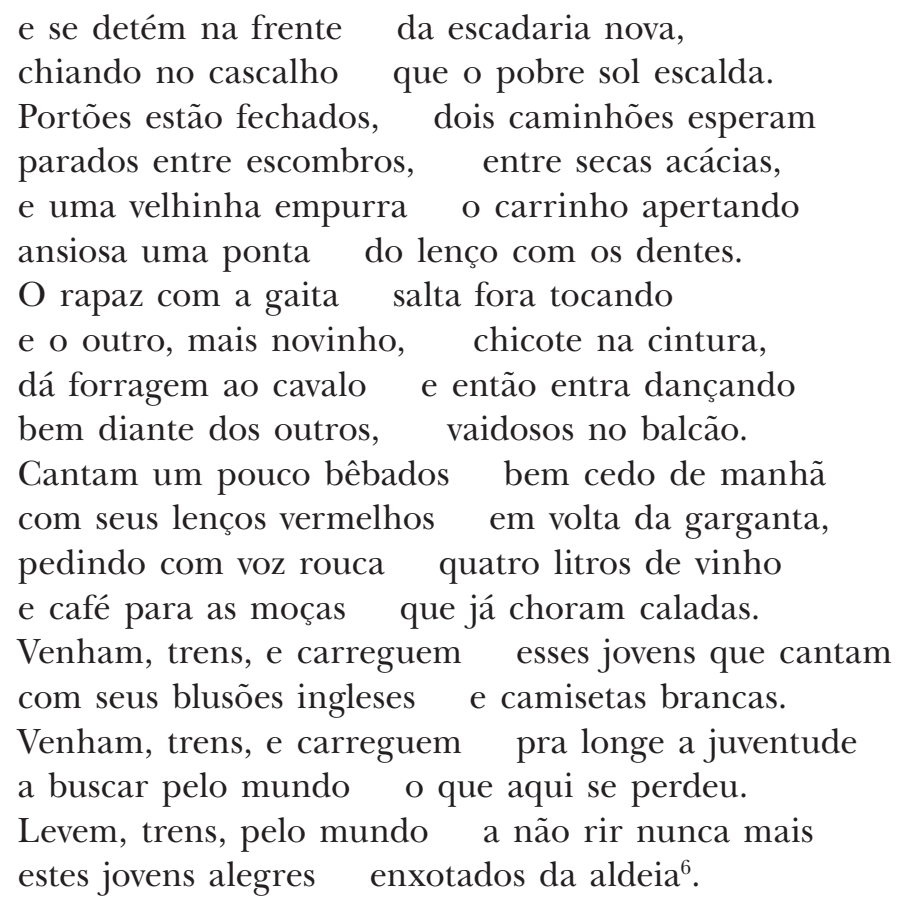

Este poema está fortemente inspirado nas leituras que Pasolini fazia à época do cancioneiro popular da poesia italiana. Não se deve esquecer que, nessa mesma época, o poeta italiano realizava a compilação desses textos que resultaria na obra Canzoniere italiano: antologia della poesia popolare (1955). Pasolini, em "A melhor juventude" utilizou de uma metrificação de enorme difusão nos anos de 600 e 700; ele operou uma métrica italiana de versos settenari, o que seria o equivalente, em nossa versificação, ao verso de seis sílabas ou hexassílabos. Nesse poema, graficamente, encontram-se numa mesma linha o conjunto de dois versos dentro dessa métrica estabelecida.

\section{POESIA EM ROMA: VIDA, ARTE E EXPERIÊNCIA}

Em 1950, acusado por uma denúncia de cunho moralista realizada ainda na região de Friuli no ano anterior, o que resultou em perseguição tanto pela direita conservadora e nacionalista, como pelo corpo diretivo do Partido Comunista Italiano, Pasolini é obrigado a deixar o seu trabalho de professor, restando a ele partir para Roma ${ }^{7}$. Apesar da grande dificuldade financeira ocasionada pela mudança, Pasolini continuou a produzir uma singular poesia. Fixado em uma região periférica de Roma, será de lá que o poeta encontrará matéria vertente para sua produção. Nesse sentido, é interessante notar um dos trechos de um poema escrito em 1951, representativo desse momento; sua primeira aparição ocorreu em 1953, no periódico Itinerari:

6. Idem, p. 33.

7. Cf. AMOROSO, Maria Betânia, op. cit., p. 21-23.
Corria no crepúsculo de lama

atrás de portos em tumulto e andaimes 
mudos, entre bairros encharcados no cheiro do ferro, panos e trapos aquecidos, que numa crosta de poeira, entre casebres de lata e manilhas, levantam muros novos e já encardidos contra um fundo de metrópole sem tinta.

\section{$[\ldots]$}

Parecia que até ali, em sua íntima, miserável morada, o homem apenas acampasse, como de uma outra raça, e apegado a esse seu arrabalde na tardinha rançosa e empoeirada não fosse Estado o seu, mas confusa pausa.

Entretanto quem passava e observava,

alheio à inocente necessidade,

procurava, estranho, uma comunhão, ao menos na festa de passar e observar.

Em torno não havia mais que a vida: mas naquele mundo morto recomeçava, para ele, a Realidade ${ }^{8}$.

Seu estilo, como se pode notar, liga-se intimamente ao cenário local de uma periferia miserável, de uma condição que talvez reflita sua própria situação de momento. Tal paisagem, todavia, por ele é estilizada sem qualquer identificação naturalista. Se, como já notou sua crítica mais especializada, a referência ao mundo é determinante para a construção das suas imagens poéticas, Pasolini, por sua vez, vai compreender que a representação do real não se faz de forma transparente, mas por um jogo de construção de linguagem. É da ação desse olhar poético que os corpos, as paisagens e as experiências se movimentam e tornam-se linguagem a decifrar.

O crítico Berardinelli apontou que esse estilo poético esteve muito alinhado à teoria pasoliniana do "experimentalismo", resultando numa modalidade única de que chamou poema narrativo. Seria um tipo de construção poética que fundiria poesia com prosa ${ }^{9}$.

Em 1956, na revista Nuovi Argomenti, Pasolini publica um de seus mais célebres poemas: "As cinzas de Gramsci". Salvo engano, na história da recepção crítica da obra do poeta italiano, esse poema é o primeiro a ser comentado no Brasil, em textos de Ruggero Jacobbi e Otto Maria Carpeaux ${ }^{10}$. Convém citar o trecho mais prestigiado de "As cinzas de Gramsci", a seção IV, de um total de seis partes do longo poema:

O escândalo de me contradizer, de estar com e contra ti; contigo no peito, à luz, contra ti nas negras entranhas;

8. PASOLINI, Pier Paolo, op. cit., pp. 53-55.

9. Cf. BERARDINELLI, Alfonso, op. cit., p. 17.

10. Cf. AMOROSO, Maria Betânia. Nós e ele: Pasolini no Brasil. In: PASOLINI, Pier Paolo, op. cit., pp. 283-290. 
de meu estado paterno traidor

- numa sombra de ação, em pensamento -,

sei que a ele me apego no calor

dos instintos, da paixão estética;

atraído pela vida proletária

mesmo antes de ti, sua alegria é

para mim religião, não sua luta

milenar; sua natureza, não sua

consciência; é a força originária

do homem, perdida enquanto se fazia,

que lhe dá um fervor da nostalgia,

uma luz poética; e outra coisa

dizer não saberia que não fosse

justa, mas insincera, abstrato

amor, não dolorosa simpatia...

Pobre entre pobres, assim como eles

me apego a esperanças humilhantes,

e como eles para viver combato

todo dia. Mas nesta condição

desesperadora de deserdado

eu possuo, possuo a mais exaltante

das possessões burguesas, o estado

mais absoluto. Mas, se possuo a história,

ela me possui, e dela me ilumino:

mas de que serve a luz ${ }^{11}$ ?

Uma das interpretações possíveis para "As cinzas de Gramsci" sugere que o poema seja uma espécie de confissão amarga de Pasolini, cujo eu lírico estaria identificado ao próprio autor. Na base dessa confissão, estaria um diálogo - a um só tempo político e pessoal - travado entre ele e a memória do grande nome da esquerda italiana, Antonio Gramsci. A dicção poética trazida pelo poema é reveladora de uma fissão do sujeito poético, o que revelaria o seu aspecto mais íntimo, contraditório, mitológico, em contraposição ao seu papel mais político, de um verdadeiro sujeito histórico. Não se pode perder de vista que, a partir da segunda metade dos anos 1950, Pasolini possa ter se desapontado com as revelações sobre o stalinismo.

O crítico Ismail Xavier, ao falar de um Pasolini teórico do cinema, talvez tenha algo a nos revelar para uma reflexão sobre o Pasolini poeta de "As cinzas 
de Gramsci”. O crítico apontou que o pensamento pasolianiano é caracterizado por uma espécie de empirismo herético. Sobre Pasolini, disse o crítico brasileiro:

Ancorado na concepção do real como linguagem, foi herético porque tal identidade não a pensou nos termos de um espelhamento puramente lógico - homologia de sistemas, encaixe de peças descarnadas -, mas a pensou como combate pelo qual o artista compromete, instalando no terreno da luta, toda a sua experiência, exigindo de si mesmo a coerência dos sinais que emite, pela presença corporal do mundo, pelo cinema que produz, pela "linguagem da ação"12.

Ligado à camada de sentido autobiográfica, que, inevitavelmente, o poema oferece aos seus leitores, está uma verve política de atuação e de engajamento, aproximando a experiência individual daquilo que seria a experiência mais coletiva de um país com profundas transformações, sobretudo no período posterior à Segunda Guerra Mundial. Não à toa, Amoroso afirmou, a partir de sua leitura de "As cinzas de Gramsci”, que “o sentido 'autobiográfico' quando se fala de Pasolini deveria então ser alargado: é um eu coral. É autobiografia e mais alguma coisa"13.

Anos depois de sua fixação em Roma, já nos anos 1960, encontra-se, com essa mesma força autobiográfica e política, um Pasolini já celebrado pelo mundo cinematográfico. É dessa época, o simbólico poema "Eu sou uma força do passado", datado de 1962 e publicado, posteriormente, no livro Poesia in forma di rosa (1964). O mesmo poema foi ainda utilizado em seu terceiro filme, La ricota (A ricota) (1963), um episódio no longa-metragem coletivo Ro.Go.Pa.G ${ }^{14}$. Segue o poema na íntegra:

Eu sou uma força do Passado.

Só na tradição consiste meu amor.

Venho dos escombros, das igrejas, dos retábulos, das aldeias

abandonadas nos Apeninos ou Pré-Alpes, onde viveram meus irmãos.

Vago pela Tuscolana feito um louco, pela Appia como um cão sem dono. Ou vejo os crepúsculos, as manhãs sobre Roma, a Ciociaria, o mundo, como os primeiros atos da Pós-História, aos quais assisto, por privilégio de registro, da borda extrema de uma era soterrada. Monstruoso é quem nasceu das entranhas duma mulher morta.

$\mathrm{E} \mathrm{eu}$, feto adulto, perambulo

Mais moderno que qualquer moderno

a buscar irmãos que não existem mais ${ }^{15}$.

O que revelaria esse poema? Pasolini mais uma vez acentua sua própria visão interior. Para revelar o eu lírico, novamente confundido à voz que pulsa

12. XAVIER, Ismail. O cinema moderno segundo Pasolini. Revista Italianística, São Paulo, ano 1, n. 1, 1993, p. 104.

13. AMOROSO, Maria Betânia, op. cit., p. 292.

14. Além de Pasolini, participaram na direção dos demais episódios os cineastas Jean-Luc Godard, Ugo Gregoretti e Roberto Rossellini.

15. PASOLINI, Pier Paolo, op. cit., p. 163. 
do poeta de carne e osso, há demonstrações de uma clara nostalgia de um mundo que ele já nota mais que transformado, é um mundo que se desintegra pela própria dinâmica da modernização e do consumo que assola o seu país de então. Restava ao poeta perambular numa Itália não mais existente, aquela representada pelo Renascimento ou pelas tradições comunais de ordem rural e popular do país. Pasolini não mais sente parte daquele espaço. Procurava por algo que só as suas reminiscências poderiam lhe oferecer. Como nos diz ao final: estava "a buscar irmãos que não existem mais". Quase só, resistia o quanto podia.

\section{REFERÊNCIAS BIBLIOGRÁFICAS}

AMOROSO, Maria Betânia. Nós e ele: Pasolini no Brasil. In: PASOLINI, Pier Paolo. Poemas: Pier Paolo Pasolini. Trad. e notas Maurício Santana Dias. Organização de Alfonso Berardinelli e Maurício Santana Dias. São Paulo: Cosac Naify, 2015.

AMOROSO, Maria Betânia. Pier Paolo Pasolini. São Paulo: Cosac Naify, 2002.

BERARDINELLI, Alfonso. Pasolini, personagem poeta. In: PASOLINI, Pier Paolo. Poemas: Pier Paolo Pasolini. Trad. e notas Maurício Santana Dias. Organização de Alfonso Berardinelli e Maurício Santana Dias. São Paulo: Cosac Naify, 2015.

PASOLINI, Pier Paolo. Poemas: Pier Paolo Pasolini. Trad. e notas Maurício Santana Dias. Organização de Alfonso Berardinelli e Maurício Santana Dias. São Paulo: Cosac Naify, 2015.

XAVIER, Ismail. O cinema moderno segundo Pasolini. Revista Italianística, São Paulo, ano 1, n. 1, 1993. 